\title{
Design of A Pilot Plant for Gasification of Biomass, Municipal and Solid Wastes
}

\author{
M. Roy, A. Knox, S. Zawaideh, J. Lawrence, S. Barghi, R. O. Buchal \\ Faculty of Engineering \\ The University of Western Ontario
}

\begin{abstract}
In 2004/2005, a team of undergraduate students undertook an interdisciplinary capstone design project to design a pilot plant to study the gasification of biomass and some forms of solid waste. Gasification is emerging as an environmentally friendly alternative to incineration for converting waste to energy and useful products. Due to the complexity of the reactions in the gasification process, a pilot plant is needed to optimize the process and to produce valuable data for the design of commercial scale units. The pilot plant was designed with a high degree of versatility to process different types of municipal and industrial solid wastes over a wide range of temperatures and pressures, e.g. $0-50$ psig and 500-1000 ${ }^{\circ} \mathrm{C}$. A fluidized bed gasifier was designed to maximize the efficiency of solid waste conversion. The oxygen level is carefully controlled to avoid oxidation of organic compounds. The solid waste is pretreated in three stages: drying, crushing and classification. A rotary dryer was designed to reduce the moisture content of the solids to the desired level, as a low level of moisture is required for gasification. The dried material is crushed to reduce the particle size. A fluidized bed reactor requires particles of certain size produced by sieving of crushed particles. Heated air or nitrogen is passed through a distributor plate below the bed to create fluidization. Electrical band heaters were designed to heat the fluidizing gas to the desired temperature. Feed enters the reactor via a screw feeder that is contained within a high pressure zone by a lock hopper. The high pressure zone prevents blowback of dangerous gasses through the feed system. A cross flow heat exchanger with finned tubes was designed to preheat the fluidizing gas. The system is designed to process up to $12 \mathrm{~kg} / \mathrm{h}$ of feed. Pressure and temperature are measured during the operation for online control of the process. An online gas chromatograph records the composition of products, which can be related to the recorded pressure and temperature and provide useful information for reactor control and enhance the selectivity of the desired product. The students performed CAD modeling of major components, and conducted a simulation study of the gasifier over a range of pressures and temperatures. The project culminated in a final design report containing detailed engineering analysis and a comprehensive set of working drawings.
\end{abstract}

